\title{
A complex procedure in the thoracic endovascular aortic repair era needs long-term follow-up to compete
}

\author{
Ourania Preventza, MD, and Joseph S. Coselli, MD
}

\footnotetext{
From the Division of Cardiothoracic Surgery, Michael E. DeBakey Department of Surgery, Baylor College of Medicine; and the Texas Heart Institute, Houston, Tex.

Disclosures: Authors have nothing to disclose with regard to commercial support.

Received for publication Aug 7, 2015; revisions received Aug 7, 2015; accepted for publication Aug 10, 2015; available ahead of print Sept 11, 2015.

Address for reprints: Ourania Preventza, MD, Division of Cardiothoracic Surgery, Michael E. DeBakey Department of Surgery, Baylor College of Medicine, One Baylor Plaza, BCM 390, Houston, TX 77030 (E-mail: opsmile01@aol.com).

J Thorac Cardiovasc Surg 2015;150:1166-7

$0022-5223 / \$ 36.00$

Copyright $(2015$ by The American Association for Thoracic Surgery

http://dx.doi.org/10.1016/j.jtcvs.2015.08.027
}

In 1997, during the era before thoracic endovascular aortic repair (TEVAR) became widely available, Palma and colleagues ${ }^{1}$ reported on a series of 70 patients treated for acute type B aortic dissection during a 7-year period (1988-1995). At that time, their innovative management was a unique concept. They placed a Dacron polyester fabric elephant trunk open and antegrade through the transverse aortic arch by way of a median sternotomy and with the patient under deep hypothermic circulatory arrest. A Dacron polyester fabric graft was sutured to the aortic wall distal to the left subclavian artery. In the latter part of their series, reflecting the trend toward the use of covered stent endovascular prostheses in the descending thoracic aorta, they implanted a stented Dacron polyester fabric endoprosthesis as an elephant trunk in 2 patients. Palma and colleagues ${ }^{1}$ were visionary in predicting that in their near future "an endoprosthesis can be implanted percutaneously in special cases of acute type B aortic dissection." Their in-hospital mortality was 20\%, and their actuarial 5-year survival was $62.5 \%$. Palma and colleagues ${ }^{1}$ advocated their technique as a therapeutic alternative for select cases of acute type B aortic dissection with retrograde progression in which the ascending aorta could be replaced and a stented Dacron polyester fabric tube could be inserted into the descending aorta to occlude the tear.

In their report in this issue of the Journal, Zhu and colleagues $^{2}$ describe a similar aggressive approach for acute type $\mathrm{B}$ dissection with distal arch involvement in which they place a stented elephant trunk antegrade into the proximal descending thoracic aorta, along with performing transposition of the left subclavian artery, through a median sternotomy with the patient under hypothermic circulatory arrest with selective cerebral perfusion. Their results were excellent; there were no in-hospital deaths, no strokes, and only 1 distal aortic intervention (thoracoabdominal aortic replacement) 5 months after the initial procedure. It should be acknowledged that the group functions in a busy, highly

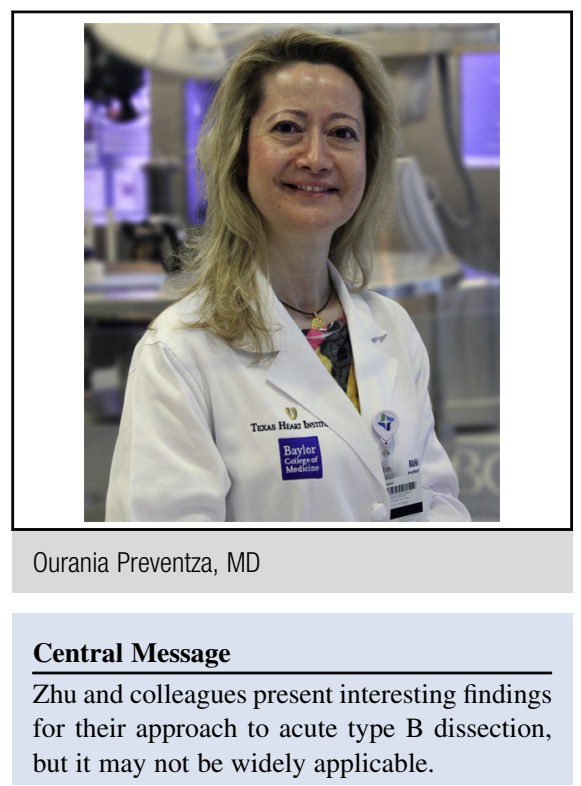

See Article page 1160. rated cardiac surgery tertiary referral center with a dedicated aortic program. Deriving any statistical interpretation and substantial conclusions from a small series of patients, however, must be done with caution. Of note, in 2 publications in the Annals of Thoracic Surgery, these authors previously described their results with the use of this technique to treat type $\mathrm{B}$ aortic dissection, both chronic $(\mathrm{n}=19$; reported in 2010) and acute $(n=24$; reported in 2012), in 2 mutually exclusive patient cohorts. The current series represents their most recent experience. A more comprehensive report of this technique that included data back to 2003 could provide more meaningful analysis and critical follow-up.

In the presented case series of 19 patients, the tear was adjacent to the origin of the left subclavian artery in 12 patients and in the proximal descending thoracic aorta distal to the origin of the left subclavian artery in 3 patients. For these 15 patients, representing $79 \%$ of the series, the implementation of hypothermic circulatory arrest and deployment of a stented elephant trunk through a median sternotomy represents a considerably more aggressive approach than would be expected unless retrograde extension was present and notable. In the TEVAR era, with or without the adjunct of left carotid-subclavian artery bypass, complicated acute type B aortic dissection can be treated endovascularly with very good results. ${ }^{3}$ The conceptual benefit of endograft stenting in acute type B aortic 
dissection requires long-term durability, and the prevention of remote complications (primarily rupture of the proximal descending thoracic aorta) is a challenging benefit to confirm in a small series of patients without long-term follow-up. In the current era, with the opportunity to use diagnostic imaging with high-resolution capabilities, such terms as "arch involvement" and "distal arch involvement" should be discarded and replaced with more precise anatomic descriptors. If the retrograde extension and involvement of the arch is distal to the left common carotid artery, provided that the tear is distal to the left subclavian, most centers will consider TEVAR with possible carotid artery-subclavian artery bypass, despite the excellent results presented by Zhu and colleagues ${ }^{2}$ in this series.

Despite excellent results of Zhu and colleagues ${ }^{2}$ with a median sternotomy and hypothermic circulatory arrest, it is important to consider the fact that many of these patients are going to receive their interventional treatment from peripheral vascular surgeons, interventional radiologists, and cardiologists. Considering the early results of ongoing trials and those soon to be implemented, branch grafting may provide a simple, less invasive solution to the problem presented by the patients in this series.

\section{References}

1. Palma JH, Almeida DR, Carvalho AC, Andrade JC, Buffolo E. Surgical treatment of acute type B aortic dissection using an endoprosthesis (elephant trunk). Ann Thorac Surg. 1997;63:1081-4.

2. Zhu JM, Qi RD, Chen L, Liu W, Li CN, Fan ZM, et al. Stented elephant trunk procedure with left subclavian artery transposition for acute type B dissection with distal arch involvement. J Thorac Cardiovasc Surg. 2015;150:1160-5.

3. Conrad MF, Carvalho S, Ergul E, Kwolek CJ, Lancaster RT, Patel VI, et al. Late aortic remodeling persists in the stented segment after endovascular repair of acute complicated type B aortic dissection. J Vasc Surg. 2015;62:600-5. 